\title{
Role of Pocket Ultrasound in Assessing Intravascular Volume to Guide Management in Heart Failure Patients with Renal Impairment
}

\author{
Wissam I. Khalife - Venkata Kishore Mukku • Aiham Albaeni • \\ Jonathan Esclovon · Ayman Elbadawi (D) - Mohamed F. Almahmoud
}

Received: April 17, 2021 / Accepted: June 11, 2021 / Published online: June 26, 2021

(c) The Author(s) 2021

\begin{abstract}
Introduction: Inpatient management of patients with heart failure (HF) and renal impairment is challenging. We sought to evaluate the role of pocket ultrasound (US)-guided management of this patient population.

Methods: We prospectively included patients with acute HF exacerbation and renal impairment admitted to the HF service in our University hospital from January 2017 to August 2018. We compared the outcomes of patients who received US-guided management with those who received standard of care management. The main study outcome was the change in estimated glomerular filtration rate
\end{abstract}

W. I. Khalife $(\varangle) \cdot$ V. K. Mukku · A. Albaeni · A. Elbadawi

Division of Cardiology, University of Texas Medical Branch, Galveston, TX, USA

e-mail: wikhalif@utmb.edu

V. K. Mukku

Department of Internal Medicine, Baton Rouge General Medical Center, Baton Rouge, LA, USA

J. Esclovon

Department of Internal Medicine, University of

Texas Medical Branch, Galveston, TX, USA

M. F. Almahmoud

Division of Cardiology, University of South

Carolina, Columbia, SC, USA
(eGFR). Multivariable logistic analysis was used to adjust for basic demographics and risk factors.

Results: A total of 211 patients with renal impairment presenting with acute HF exacerbation (mean age $66.8 \pm 14.6$ years, $41 \%$ females, $62 \%$ white) were enrolled in the study, of whom $69(32.7 \%)$ received US-guided management and $151(68 \%)$ received standard of care management. The change in the eGFR was significantly lower in US-guided group than in the group receiving standard of care $(1.1 \pm 4.3 \%$ vs. $-11.15 \pm 2.9 \% ; p=0.04)$. No significant difference was observed between the patient groups in the length of stay $(6.45 \pm 0.38$ vs. $6.44 \pm 0.56$; days; $p=0.98$ ) and in the 30-day HF readmission rate (hazard ratio 1.27 , 95\% confidence interval 0.28-5.6; $p=0.75$ ).

Conclusion: Ultrasound-guided management of patients admitted with acute HF exacerbation and renal impairment may be beneficial in preserving kidney function. US provides a simple easily accessible tool to guide the management of patients with HF.

Keywords: Heart failure; Ultrasound; Renal impairment 


\section{Key Summary Points}

The aim of this prospective study was to evaluate the role of pocket ultrasound (US) in the management of patients with heart failure (HF) and renal impairment.

In patients with HF and renal impairment, change in the estimated glomerular filtration rate (eGFR) was significantly more favorable in the US-guided management group than in the group of patients receiving standard of care management.

We found no difference in the length of hospital stay or in 30-day readmissions between the study groups.

US-guided management of patients admitted with acute HF exacerbation and renal impairment may be beneficial in preserving kidney function.

\section{DIGITAL FEATURES}

This article is published with digital features, including a summary slide, to facilitate understanding of the article. To view digital features for this article go to https://doi.org/10.6084/ m9.figshare.14762058

\section{INTRODUCTION}

Heart failure (HF) is one of the leading causes of emergency department visits and hospitalization in patients with chronic kidney disease (CKD) [1]. Renal impairment is a strong and independent risk factor for cardiovascular disease. The prevalence of CKD ranges from 39 to $60 \%$ in HF patients and is associated with increased mortality and morbidity [2, 3], with nearly $50 \%$ of deaths in the CKD patient population due to cardiovascular causes [4]. HF prevalence increases with declining kidney function [5], and the Acute Decompensated HF

National Registry (ADHERE) showed that approximately $30 \%$ of patients admitted to hospital for acute decompensated HF have acute or chronic renal insufficiency [6].

HF management in patients with CKD is challenging [7-9]. Early HF symptoms, such as vascular congestion, are difficult to diagnose, especially in patients with CKD [9]. Increase of intracardiac filling pressures, which happens over days to weeks before the development of clinical symptoms or weight changes, often precede admissions for HF. Physicians often have difficulty in identifying early signs of $\mathrm{HF}$, especially intravascular changes [10]. Traditional tests, such as chest X-ray, and biomarkers, such as N-terminal pro-b-type natriuretic peptide (NT pro-BNP) and high-sensitivity troponin $\mathrm{T}$ (hs-TnT), are often difficult to interpret in patients with CKD and early-stage renal disease (ESRD) [11]. Clinical trials designed to evaluate the role of biomarkers in directing medical therapy have shown conflicting results $[12,13]$. The gold standard test for determining cardiac congestion is cardiac catheterization, a procedure that is invasive, time consuming and costly [14]. Therefore, there is an emerging need to investigate new modalities, such as pocket ultrasound (PUS), for assessing volume status. The aim of this study was to evaluate the impact of US-guided management of acute HF exacerbation in patients with renal impairment.

\section{METHODS}

This was a prospective interventional study of HF patients admitted to an advanced HF ward. The protocol was approved by the institutional review board at the University of Texas Medical Branch, Galveston, TX, USA. Informed patient consent to participate in the study was obtained by a team of physicians prior to the performance of US. The study was performed in accordance with the Helsinki Declaration of 1964 and its later amendments. We included patients admitted with acute HF exacerbation [New York Heart Association (NYHA) class III or IV] to the hospital from 1 January 2017 to 31 August 2017. HF exacerbation was ascertained by advanced HF specialists after assessment of 
patients' history, echocardiographic data and BNP measurements. We included patients aged $>18$ years, non-pregnant, with a history of $\mathrm{HF}$ and renal impairment defined by an estimated glomerular filtration rate (eGFR) of $<$ $60 \mathrm{~mL} / \mathrm{min}$ per $1.73 \mathrm{~m}^{2}$. We excluded patients with trauma, acute myocardial infarction or those with other causes of dyspnea that are clearly caused by other conditions, such as pulmonary embolism or pneumothorax. For the purpose of this study, patients were divided into two groups: a group with US-guided management of HF exacerbation and a group receiving standard of care management. The decision to enroll patients into the US-guided management group was based on the availability of the cardiologist performing the US.

A hand-held pocket ultrasound machine (Vscan with Dual Probe; model GM000310; GE Vingmed Ultrasound, Horten, Norway) with 3.5-MHz multiphase array probe was used. The US examination was always performed at bedside, at the initial encounter with the patient and repeated whenever there was unclarity regarding the clinical volume status of the patient. The results were interpreted by a cardiologist specialized in advanced HF. US was used to assess the diameter and compressibility of the inferior vena cava (IVC) and right internal jugular vein (IJ) and respiratory variations. All US examinations were done using the same US machine. The IVC was imaged from the subxiphoid window and the IJ was imaged from the right side of the neck. Respiratory variations were examined by recording the M-mode and asking the patient to sniff. Central venous pressure (CVP) was estimated based on US evaluation and classified as follows: (1) if maximal IVC or IJ diameters were $>2 \mathrm{~cm}$ and compressibility and respiration variation were both $<50 \%$, then the CVP was estimated to be $>10 \mathrm{mmHg}$; (2) if maximal IVC and IJ diameters were $<2 \mathrm{~cm}$ and compressibility and respiratory variation were both $>50 \%$, then the CVP was estimated to be $<5 \mathrm{mmHg}$; (3) if the conditions above were not met, then the CVP was estimated as $5-10 \mathrm{mmHg}$. The results of US exams were provided to the primary advanced HF team. Based on these results the primary team adjusted the diuretics dosage.
The baseline demographic and patient characteristics data, medical history, laboratory findings and imaging results were collected. All data were reviewed and stored in the electronic medical records at the University of Texas Health System. Baseline eGFR and discharge eGFR were measured for each patient and the percentage change in eGFR was determined. Our primary outcome was the difference in the change in eGFR during the index hospitalization between the patient group receiving USguided management and that receiving standard of care management. Other secondary endpoints included the length of hospital stay and 30-day HF readmission.

Continuous variables were presented as the mean $[ \pm$ standard deviation (SD)], and unpaired student $t$ tests were used to compare the difference between the patient group receiving USguided management and the patient group receiving standard of care. Chi-square $\left(\chi^{2}\right)$ tests were used for analysis of the categorical variables. Multivariable linear regression analysis was used to compare the percentage change in eGFR and length of stay. Multivariable binary logistic regression analysis was used to compare 30-day HF readmissions between the two groups. Proportional hazard regression models were used to estimate the hazard ratios (HR) of HF readmission between the two groups. For all multivariable regression analyses, two models were adopted: model 1 was unadjusted, and model 2 was adjusted for age, sex, race, body mass index (BMI), hypertension and diabetes. A value of $p<0.05$ was considered to be significant. Analyses were carried out using IBM SPSS Statistics for Windows, version 25.0 (release 2016; IBM Corp., Armonk, NY, USA).

\section{RESULTS}

A total of 222 patients were enrolled during the inclusion period, among whom 71 were included in the US-guided management group and 151 were included in the standard of care management group. Baseline characteristics are presented in Table 1 . The overall cohort had a mean $( \pm S D)$ age of $66.8 \pm 14.6$ years, $41 \%$ were female and $62 \%$ were of white race. No 
Table 1 Baseline characteristics of study population

\begin{tabular}{|c|c|c|c|}
\hline Variable & Standard care group $(N=151)$ & US-guided group $(N=71)$ & $p$ value \\
\hline Age (years) & $67.7 \pm 14.6$ & $64.7 \pm 14.6$ & 0.15 \\
\hline Sex (male) & $86(57 \%)$ & $46(65 \%)$ & 0.3 \\
\hline $\operatorname{BMI}\left(\mathrm{kg} / \mathrm{m}^{2}\right)$ & $32.1 \pm 8$ & $31.4 \pm 7.6$ & 0.55 \\
\hline \multicolumn{4}{|l|}{ Race } \\
\hline White & $93(60 \%)$ & $41(58 \%)$ & \multirow[t]{3}{*}{0.5} \\
\hline Black & $45(30 \%)$ & $26(37 \%)$ & \\
\hline Other ethnicity & $13(9 \%)$ & $4(6 \%)$ & \\
\hline Hypertension & $149(99 \%)$ & $67(94 \%)$ & 0.07 \\
\hline Diabetes & $80(53 \%)$ & $32(45 \%)$ & 0.27 \\
\hline Current or former smoker & $55(36 \%)$ & $23(32 \%)$ & 0.85 \\
\hline Hyperlipidemia & $99(66 \%)$ & $55(77 \%)$ & 0.07 \\
\hline Baseline eGFR (mL/min per $\left.1.73 \mathrm{~m}^{2}\right)$ & $54.6 \pm 23.5$ & $50.7 \pm 22.2$ & 0.21 \\
\hline Discharge eGFR $\left(\mathrm{mL} / \mathrm{min}\right.$ per $\left.1.73 \mathrm{~m}^{2}\right)$ & $46.3 \pm 18.7$ & $47.3 \pm 20$ & 0.72 \\
\hline NT-BNP $(p g / m L)$ & $9374 \pm 10,891$ & $9587 \pm 13,048$ & 0.93 \\
\hline Ischemic cardiomyopathy & $37(24.5 \%)$ & $24(33.8 \%)$ & 0.28 \\
\hline LVEF $<40 \%$ & $85(56.7 \%)$ & $49(69 \%)$ & 0.21 \\
\hline \multicolumn{4}{|l|}{ NYHA class } \\
\hline III & $139(92 \%)$ & $55(77 \%)$ & \multirow[t]{2}{*}{0.002} \\
\hline IV & $12(8 \%)$ & $16(23 \%)$ & \\
\hline \multicolumn{4}{|l|}{ Medication details } \\
\hline Prior beta blocker use & $43(28.5 \%)$ & $20(28.2 \%)$ & 0.548 \\
\hline Prior ACEI/ARB use & $92(60.9 \%)$ & $33(46.5 \%)$ & 0.06 \\
\hline Prior loop diuretics & $35(23.2 \%)$ & $15(21.1 \%)$ & 0.863 \\
\hline Prior MRA & $145(96.0 \%)$ & $60(84.5 \%)$ & 0.004 \\
\hline Prior digitalis & $139(92.1 \%)$ & $54(76.1 \%)$ & 0.001 \\
\hline Initiated vasodilators & $145(96 \%)$ & $58(81.7 \%)$ & 0.001 \\
\hline Any contrast study upon admission & $65(91.5 \%)$ & $50(72.5 \%)$ & 0.36 \\
\hline
\end{tabular}

Values in table are presented as the mean \pm standard deviation (SD) or as the number (of patients) with the percentage in parenthesis

$A C E I / A R B$ Angiotensin-converting enzyme inhibitor/angiotensin II receptor blocker, $B M I$ body mass index, $C A D$ coronary artery disease, $e G F R$ estimated glomerular filtration rate, $L V E F$ left ventricular systolic function, $M R A$ magnetic resonance angiogram, NT-BNP N-terminal brain natriuretic peptide, NYHA New York Heart Association, US ultrasound 
Table 2 Outcomes of standard care versus US-guided management of heart failure patients with chronic kidney disease

\begin{tabular}{lllll}
\hline Outcome & Model $^{\mathbf{a}}$ & Standard of care group & US-guided management group & $\boldsymbol{p}$ value \\
\hline Percentage eGFR change & Model 1 & $-11.15 \pm 2.9$ & $1.1 \pm 4.3$ & 0.02 \\
& Model 2 & $-10.75 \pm 2.9$ & $-0.1 \pm 4.2$ & 0.04 \\
\multirow{2}{*}{ Length of stay (days) } & Model 1 & $6.4 \pm 0.37$ & $6.51 \pm 0.54$ & 0.87 \\
& Model 2 & $6.45 \pm 0.38$ & $6.44 \pm 0.56$ & 0.98 \\
30-Day readmission for heart failure & Model 1 & $0.84(0.31-2.25)$ & Reference & 0.725 \\
& Model 2 & $1.27(0.28-5.6)$ & Reference & 0.753 \\
\hline
\end{tabular}

Values in table are presented as the mean \pm SD unless indicated otherwise

a Model 1: unadjusted model; Model 2: model adjusted for age, sex, race, BMI, hypertension and diabetes

b Values presented as the hazard ratio with the $95 \%$ confidence interval in parenthesis

significant differences were observed between the two study groups in age, sex, ethnicity, BMI, hypertension, diabetes, smoking status, hyperlipidemia, baseline eGFR, coronary artery disease status and NT-BNP. More patients in the US-guided group were considered to be NYHA class IV ( 23 vs. $8 \% ; p=0.002)$.

In the unadjusted model, there was a significant difference in the percentage change in eGFR during the hospital stay between the standard care and US-guided groups, with the standard care group showing a $-11.15 \pm 2.9 \%$ decline in eGFR and the US-guided group experiencing no significant change in eGFR $(1.1 \pm 4.3 \%)(p=0.02)$ (Table 2$)$. Similar results were observed in the adjusted model $(p=0.04)$. No significant difference was observed in the length of stay between the two groups in both the unadjusted and adjusted models $(p=0.87$ and $p=0.98$, respectively). There was no significant difference in 30-day readmissions for HF between the standard care and US-guided groups (9.9 vs. 8.5\%; HR 0.84, 95\% confidence interval 0.31-2.25; $p=0.752$ ) (Fig. 1).

\section{DISCUSSION}

In this prospective study including 222 patients with renal impairment admitted for acute HF exacerbation, our aim was to evaluate the comparative outcomes of US-guided management and standard of care management. Our main outcome, namely change in the eGFR, was significantly more favorable in the US-guided management group. We found no difference in the length of hospital stay or in 30-day readmissions between both study groups (Fig. 2).

The interaction between HF and renal disease is complex and bidirectional. HF is associated with a high risk of renal dysfunction and the development of CKD [15-17], and renal dysfunction on its own is associated with progression of HF [18]. Moreover, the management of patients with HF who have renal impairment is challenging. In addition, guidelines for the management of $\mathrm{HF}$ in the general population may not apply entirely to those with CKD, as most of the randomized trials conducted to date have excluded patients with severe renal impairment [20]. Key strategies to reduce both the risk and manifestation of $\mathrm{HF}$ in patients with CKD are maintaining salt and water balance and improving blood pressure control [21]. Diuretic therapy often requires higher doses in HF patients with CKD than in HF patients with normal kidney function [22], due to a resistance to loop diuretics in patients with advanced CKD. Patients with CKD are vulnerable in that renal function may worsen upon diuretic administration. Acute worsening of renal function during the treatment of HF patients is a strong independent predictor of long-term adverse outcomes [23-25]. Treatment to relieve congestive symptoms of HF is limited by further decline in renal function. Patients with 


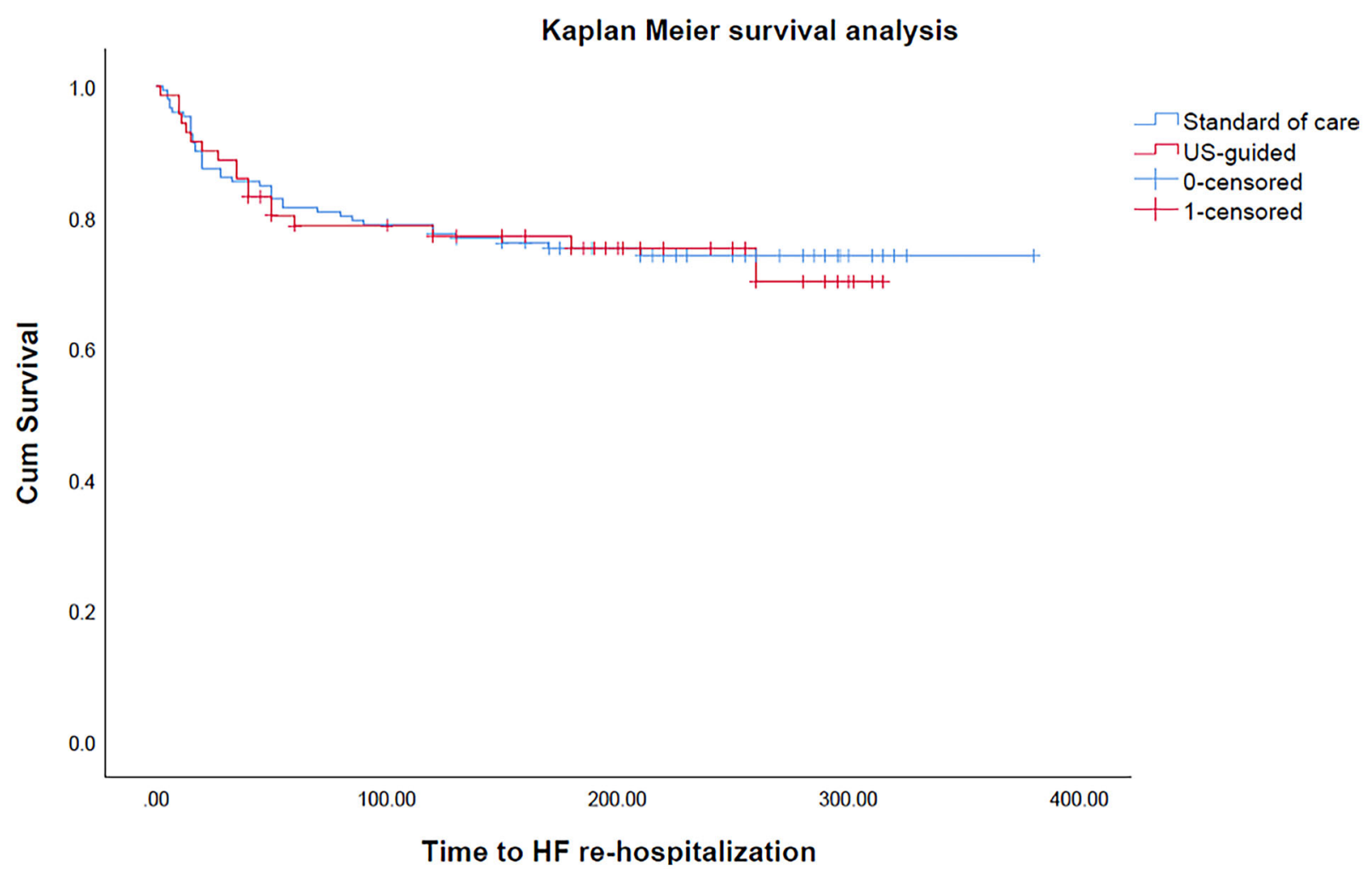

Fig. 1 Kaplan-Meier analysis for time free of re-hospitalization between heart failure (HF) patients receiving standard of care management and ultrasound (US)-guided management, respectively

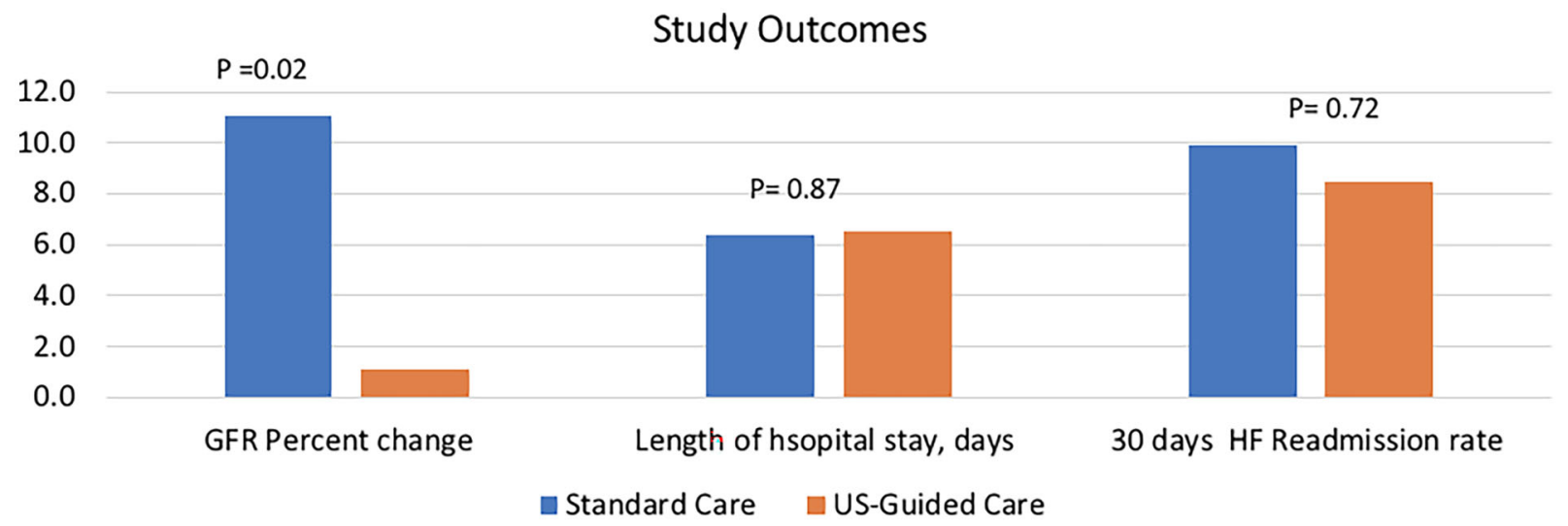

Fig. 2 Comparison of clinical outcomes between HF patients receiving standard of care management and those receiving US-guided management. GFR Glomerular filtration rate

worsening renal function often require a longer stay in the hospital [26].

The Evaluation Study of Congestive Heart Failure and Pulmonary Artery Catheterization Effectiveness (ESCAPE) trial demonstrated that renal function did not worsen when treatment was directed at lowering invasively measured CVP and pulmonary capillary wedge pressure, compared to clinical assessment alone [27, 28]. Renal dysfunction contributes substantially to morbidity and mortality in patients with HF [29]. The Chronic Renal Insufficiency Cohort 
(CRIC) study showed that HF in patients with CKD was independently associated with a $29 \%$ higher risk of progression to ESRD or a $50 \%$ decline in eGFR compared with those without HF [30]. Therefore, preventive and treatment strategies are needed to preserve renal function in patients with HF [31]. These results led to use of new modalities, such as PUS, in the management of HF patients to better assess volume status. In the present study, we hypothesize that utilization of PUS in measuring IVC diameter along with the collapsibility of the IVC and internal jugular veins will provide a more precise assessment of volume status, guide treatment of HF patients, significantly decrease hospital readmissions, improve patient's quality of life and prevent hospital complications.

PUS is an easy, noninvasive strategy to measure IVC diameter and collapsibility. IVC diameter is a marker of venous congestion and a strong predictor of HF prognosis. Together, IVC diameter and collapsibility provide better prognostic information than NT-proBNP [32]. Studies have shown that IVC responds more quickly to intravenous diuresis than BNP [33]. IVC diameter together with internal jugular vein collapsibility measurement provides a noninvasive estimate of right atrial pressure [34, 35]. Prior studies have shown that IVC diameter correlates with right atrial pressure and pulmonary capillary wedge pressure (PCWP) $[36,37]$. Besli et al. showed that IVC diameter was higher among patients with decompensated HF when compared to those with compensated HF. Therefore, IVC diameter is a valuable tool to distinguish decompensated HF patients from compensated HF [38].

Khandwalla et al. showed that greater IVC dilation was associated with a higher risk of HF hospitalization [39]. These authors found a 38\% increased risk of HF hospitalization for every $0.5-\mathrm{cm}$ increase in mean IVC diameter. The risk of HF readmission increased significantly for an IVC diameter of between 2 and 2.49 compared a diameter of $<2 \mathrm{~cm}$ [39]. Therefore, IVC diameter can predict volume status and risk of $\mathrm{HF}$ admission. Moreover, changes in IVC size also correlate with a reduction in PCWP in patients treated for acute decompensation of HF [40]. In this prospective single-center study, we found
US-guided management of patients with HF and CKD to be superior to standard care in terms of preservation of kidney function; in contrast no significant difference was shown for length of stay or future readmission. Randomized studies with a longer follow-up may be needed to determine the impact of US-guided management on the progression of renal impairment and the risk of HF readmission.

The results of this study should be taken into cosideration in light of some limitations. First, the study was not randomized prior to enrolment which may have created allocation bias that could not be excluded. We attempted to reduced bias by conducting multivariable logistic regression analysis to adjust for baseline characteristics and comorbidities. Second, the cardiology team was not blinded to which patients had US-guided management and were provided with the US results. However, enrolled patients were managed by an advanced HF team and received guideline-directed medial therapy. Third, no data were collected on which patients had standard transthoracic echocardiogram at the index hospitalization as we felt this examination is a part of standard management when it is indicated. Furthermore, no comparison was made on the dose and type of diuretic therapy given, which may limit the generalization of our observations. Finally, while we collected data on short-term eGFR change during the hospital stay, we did not collect data on longterm eGFR change. However, despite the shortterm follow-up and small sample size, the utilization of handheld US provides valuable information that can guide medical management of high-risk HF patients with CKD.

\section{CONCLUSION}

Ultrasound-guided management of patients admitted with acute HF exacerbation and renal impairment may be beneficial in preserving kidney function. Randomized studies with longer follow-up may be needed to determine the impact on the progression of renal impairment and the risk of hospital readmission for HF. 


\section{ACKNOWLEDGEMENTS}

Authorship. All named authors meet the International Committee of Medical Journal Editors (ICMJE) criteria for authorship for this article, take responsibility for the integrity of the work as a whole, and have given their approval for this version to be published.

Authors contributions. Wissam I Khalife contributed to study conception, writing the article, critical revision of the article, final approval of the article and logistical/ technical support. Venkata Kishore Mukku contributed to study conception, data collection, writing the article, critical revision of the article and final approval of the article. Aiham Albaeni contributed to data collection, analysis and interpretation, writing the article, critical revision of the article and final approval of the article. Jonathan Esclovon contributed to data collection, writing the article, critical revision of the article and final approval of the article. Ayman Elbadawi contributed to data collection, writing the article, critical revision of the article and final approval of the article. Mohamed $\mathrm{F}$ Almahmoud contributed to data collection, analysis and interpretation, writing the article, critical revision of the article and final approval of the article.

Funding. No funding or sponsorship was received for this study or publication of this article.

Disclosures. Wissam I Khalife, Venkata Kishore Mukku, Aiham Albaeni, Jonathan Esclovon, Ayman Elbadawi and Mohamed F Almahmoud have nothing to disclose.

Compliance with Ethics Guidelines. The protocol was approved by the institutional review board at University of Texas Medical Branch, Galveston, TX, USA. Informed patient consent to participate in the study was obtained by a team of physicians prior to the performance of US. The study was performed in accordance with the Helsinki Declaration of 1964 and its later amendments.
Data Availability. All data generated or analyzed during this study are included in this published article/as supplementary information files.

Open Access. This article is licensed under a Creative Commons Attribution-NonCommercial 4.0 International License, which permits any non-commercial use, sharing, adaptation, distribution and reproduction in any medium or format, as long as you give appropriate credit to the original author(s) and the source, provide a link to the Creative Commons licence, and indicate if changes were made. The images or other third party material in this article are included in the article's Creative Commons licence, unless indicated otherwise in a credit line to the material. If material is not included in the article's Creative Commons licence and your intended use is not permitted by statutory regulation or exceeds the permitted use, you will need to obtain permission directly from the copyright holder. To view a copy of this licence, visit http://creativecommons.org/licenses/by$\mathrm{nc} / 4.0 /$.

\section{REFERENCES}

1. Ronksley PE, Tonelli M, Manns BJ, et al. Emergency department use among patients with CKD: a population-based analysis. Clin J Am Soc Nephrol. 2017;12:304-14.

2. Ezekowitz J, McAlister FA, Humphries KH, et al. The association among renal insufficiency, pharmacotherapy, and outcomes in 6,427 patients with heart failure and coronary artery disease. J Am Coll Cardiol. 2004;44:1587-92.

3. Smith GL, Lichtman JH, Bracken MB, et al. Renal impairment and outcomes in heart failure: systematic review and meta-analysis. J Am Coll Cardiol. 2006;47:1987-96.

4. Briasoulis A, Bakris GL. Chronic kidney disease as a coronary artery disease risk equivalent. Curr Cardiol Rep. 2013;15:340.

5. Bagshaw SM, Cruz DN, Aspromonte N, et al; Acute Dialysis Quality Initiative Consensus Group. Epidemiology of cardio-renal syndromes: workgroup statements from the 7th ADQI Consensus Conference. Nephrol Dial Transplant. 2010;25(5):1406-16 
6. Adams KF Jr, Fonarow GC, Emerman CL, et al; ADHERE Scientific Advisory Committee and Investigators. Characteristics and outcomes of patients hospitalized for heart failure in the United States: rationale, design, and preliminary observations from the first 100,000 cases in the Acute Decompensated Heart Failure National Registry (ADHERE). Am Heart J. 2005;149(2):209-16.

7. Bansal N, Katz R, Robinson-Cohen C, et al. Absolute rates of heart failure, coronary heart disease, and stroke in chronic kidney disease: an analysis of 3 community-based cohort studies. JAMA Cardiol. 2017;2(3):314-8.

8. Kottgen A, Russell SD, Loehr LR, et al. Reduced kidney function as a risk factor for incident heart failure: the atherosclerosis risk in communities (ARIC) study. J Am Soc Nephrol. 2007;18(4): 1307-15.

9. Tuegel C, Bansal N. Heart failure in patients with kidney disease. Heart. 2017;103(23):1848-53.

10. Zile MR, Bennett TD, St John Sutton M, et al. Transition from chronic compensated to acute decompensated heart failure: pathophysiological insights obtained from continuous monitoring of intracardiac pressures. Circulation. 2008;118(14): 1433-41.

11. Park M, Hsu CY, Li Y, et al. Chronic Renal Insufficiency Cohort (CRIC) Study Group. Associations between kidney function and subclinical cardiac abnormalities in CKD. J Am Soc Nephrol. 2012;23(10):1725-34.

12. Desai AS. Are serial BNP measurements useful in heart failure management? Serial natriuretic peptide measurements are not useful in heart failure management: the art of medicine remains long. Circulation. 2013;127(4):509-16.

13. Januzzi JL, Troughton R. Are serial BNP measurements useful in heart failure management? Serial natriuretic peptide measurements are useful in heart failure management. Circulation. 2013;127(4):500-7 (discussion 508).

14. Volpicelli G, Elbarbary M, Blaivas $M$, et al. International liaison committee on lung ultrasound (ILC-LUS) for international consensus conference on lung ultrasound (ICC-LUS). International evidence-based recommendations for point-of-care lung ultrasound. Intensive Care Med. 2012;38(4): 577-91.

15. Waldum B, Westheim AS, Sandvik L, et al. Renal function in outpatients with chronic heart failure. J Card Fail. 2010;16(5):374-80.
16. De Silva R, Nikitin NP, Witte KK, et al. Incidence of renal dysfunction over 6 months in patients with chronic heart failure due to left ventricular systolic dysfunction: contributing factors and relationship to prognosis. Eur Heart J. 2006;27(5):569-81.

17. Michel A, Martin-Perez M, Ruigomez A, Garcia Rodriguez LA. Incidence and risk factors for severe renal impairment after first diagnosis of heart failure: a cohort and nested case-control study in UK general practice. Int J Cardiol. 2016;207:252-7.

18. Foster MC, Rawlings AM, Marrett E, et al. Cardiovascular risk factor burden, treatment, and control among adults with chronic kidney disease in the United States. Am Heart J. 2013;166(1):150-6.

19. Weiner DE, Tighiouart H, Amin MG, et al. Chronic kidney disease as a risk factor for cardiovascular disease and all-cause mortality: a pooled analysis of community-based studies. J Am Soc Nephrol. 2004;15(5):1307-15.

20. Wang AY, Sanderson JE. Treatment of heart failure in long-term dialysis patients: a reappraisal. Am J Kidney Dis. 2011;57(5):760-72.

21. Ritz E, Dikow R, Adamzcak M, Zeier M. Congestive heart failure due to systolic dysfunction: the Cinderella of cardiovascular management in dialysis patients. Semin Dial. 2002;15(3):135-40.

22. Herzog CA, Asinger RW, Berger AK, et al. Cardiovascular disease in chronic kidney disease: a clinical update from kidney disease: improving global outcomes (KDIGO). Kidney Int. 2011;80(6):572-86.

23. Forman DE, Butler J, Wang Y, et al. Incidence, predictors at admission, and impact of worsening renal function among patients hospitalized with heart failure. J Am Coll Cardiol. 2004;43(1):61-7.

24. Hillege HL, Girbes AR, de Kam PJ, et al. Renal function, neurohormonal activation, and survival in patients with chronic heart failure. Circulation. 2000;102(2):203-10.

25. Krumholz HM, Chen YT, Vaccarino V, et al. Correlates and impact on outcomes of worsening renal function in patients $>$ or $=65$ years of age with heart failure. Am J Cardiol. 2000;85(9):1110-3.

26. Cowie MR, Komajda M, Murray-Thomas T, Underwood J, Ticho B, POSH Investigators. Prevalence and impact of worsening renal function in patients hospitalized with decompensated heart failure: results of the prospective outcomes study in heart failure (POSH). Eur Heart J. 2006;27(10):1216-22.

27. Binanay C, Califf RM, Hasselblad V, et al; ESCAPE Investigators and ESCAPE Study Coordinators. Evaluation study of congestive heart failure and 
pulmonary artery catheterization effectiveness: the ESCAPE trial. JAMA. 2005;294(13):1625-33.

28. Nohria A, Hasselblad V, Stebbins A, et al. Cardiorenal interactions: insights from the ESCAPE trial. J Am Coll Cardiol. 2008;51(13):1268-74.

29. Go AS, Chertow GM, Fan D, McCulloch CE, Hsu CY. Chronic kidney disease and the risks of death, cardiovascular events, and hospitalization. N Engl J Med. 2004;351(13):1296-305.

30. Rahman M, Xie D, Feldman HI, et al; CRIC Study Investigators. Association between chronic kidney disease progression and cardiovascular disease: results from the CRIC Study. Am J Nephrol. 2014;40(5):399-407

31. Damman K, Testani JM. The kidney in heart failure: an update. Eur Heart J. 2015;36(23):1437-44.

32. Pellicori P, Carubelli V, Zhang J, et al. IVC diameter in patients with chronic heart failure: relationships and prognostic significance. JACC Cardiovasc Imaging. 2013;6(1):16-28.

33. Yavaşi Ö, Ünlüer EE, Kayayurt K, et al. Monitoring the response to treatment of acute heart failure patients by ultrasonographic inferior vena cava collapsibility index. Am J Emerg Med. 2014;32(5): 403-7.

34. Kircher BJ, Himelman RB, Schiller NB. Noninvasive estimation of right atrial pressure from the inspiratory collapse of the inferior vena cava. Am J Cardiol. 1990;66(4):493-6.
35. Kimura BJ, Shaw DJ, Agan DL, Amundson SA, Ping AC, DeMaria AN. Value of a cardiovascular limited ultrasound examination using a hand-carried ultrasound device on clinical management in an outpatient medical clinic. Am J Cardiol. 2007;100(2):321-5.

36. Brennan JM, Blair JE, Goonewardena S, et al. Reappraisal of the use of inferior vena cava for estimating right atrial pressure. J Am Soc Echocardiogr. 2007;20(7):857-61.

37. Blair JE, Brennan JM, Goonewardena SN, Shah D, Vasaiwala S, Spencer KT. Usefulness of hand-carried ultrasound to predict elevated left ventricular filling pressure. Am J Cardiol. 2009;103(2):246-7.

38. Besli F, Kecebas M, Caliskan S, Dereli S, Baran I, Turker Y. The utility of inferior vena cava diameter and the degree of inspiratory collapse in patients with systolic heart failure. Am J Emerg Med. 2015;33(5):653-7.

39. Khandwalla RM, Birkeland KT, Zimmer R, et al. Usefulness of serial measurements of inferior vena cava diameter by Vscan ${ }^{\mathrm{TM}}$ to identify patients with heart failure at high risk of hospitalization. Am J Cardiol. 2017;119(10):1631-6.

40. Ramasubbu K, Deswal A, Chan W, Aguilar D, Bozkurt B. Echocardiographic changes during treatment of acute decompensated heart failure: insights from the ESCAPE trial. J Card Fail. 2012;18(10): 792-8. 